\title{
Insights into the Influence of Fluorination Positions on Polymer Donor Materials on Photovoltaic Performance
}

\author{
Xue Gong, ${ }^{\mathrm{a}}$ Guangwu Li, ${ }^{\mathrm{a}}$ Jianya Chen, ${ }^{\mathrm{b}}$ Shiyu Feng, ${ }^{\mathrm{a}}$ Danyang Ma, ${ }^{\mathrm{c}}$ Ran Hou, ${ }^{\mathrm{a}}$ \\ Cuihong Li, ${ }^{\text {a }}$ Wei Ma, ${ }^{\mathrm{b}}$ Zhishan $\mathrm{Bo}^{* \mathrm{a}}$
}

\begin{abstract}
${ }^{a}$ Beijing Key Laboratory of Energy Conversion and Storage Materials, College of Chemistry, Beijing Normal University, Beijing 100875, China **(C.L.) Email: licuihong@bnu.edu.cn. (Z.B.) Email: zsbo@bnu.edu.cn.
\end{abstract}

${ }^{\mathrm{b}}$ State Key Laboratory for Mechanical Behavior of Materials, Xi'an Jiaotong University, Xi'an 710049, China

${ }^{c}$ State Key Laboratory of Chemical Resource Engineering, Beijing University of Chemical Technology, Beijing 100029, China 


\begin{abstract}
To explore the influence of fluoro substitution position and number on optical, electrochemical and photovoltaic properties, three novel donor-acceptor (D-A) alternative copolymers (PHF, PFH and PFF) were synthesized by Stille polycondensation of 2,3-diphenyl-5,8-di(thiophen-2-yl)quinoxaline (DTQx) acceptor unit and indacenodithiophene (IDT) donor unit. As films, PHF and PFF comprising two fluoro substituents on the lateral phenyl groups displayed a broad absorption ranging from 350 to $700 \mathrm{~nm}$; whereas PFH containing two fluorine atoms on the polymer main chain exhibited a slightly narrower absorption ranging from 350 to 650 $\mathrm{nm}$. In addition, fluoro substitution on the polymer main chain can lower the HOMO level of the resulted polymers. As expected, PFH and PFF possess deeper HOMO energy level than PHF. Polymer solar cells (PSCs) were fabricated with these three polymers as donor materials and $\mathrm{PC}_{71} \mathrm{BM}$ as acceptor material. PHF based PSCs gave a power conversion efficiency (PCE) of $7.2 \%$ with a $V_{\text {oc }}$ of $0.84 \mathrm{~V}$, a $J_{\text {sc }}$ of 12.46 $\mathrm{mA} / \mathrm{cm}^{2}$ and an $F F$ of 0.69 . And PFH based PSCs showed a PCE of $6.19 \%$ with a $V_{\text {oc }}$ of $0.93 \mathrm{~V}$, a $J_{\mathrm{sc}}$ of $9.57 \mathrm{~mA} / \mathrm{cm}^{2}$ and an FF 0.70 . However, a PCE of only $2.9 \%$ with a $V_{\text {oc }}$ of $0.92 \mathrm{~V}$, a $J_{\mathrm{sc}}$ of $4.61 \mathrm{~mA} / \mathrm{cm}^{2}$ and an $F F$ of 0.68 was obtained for PFF based PSCs. Transmission electron microscopy (TEM) and resonant soft X-ray scattering (R-SoXS) studies indicated that the introduction of four fluorine atoms at each repeating unit can spoil the morphology of active layer. These results highlight the importance of fluorination position and number to the performance of PSCs.
\end{abstract}

\title{
Keywords:
}

Polymer solar cells, fluorination position and number, morphology 


\section{Introduction}

Polymer solar cells (PSCs) with a bulk heterojunction (BHJ) structure by blending a $p$-type donor material and an $n$-type acceptor material as the active layer have attracted particular attention in the past decades. ${ }^{1-4}$ Power conversion efficiency (PCE) of single junction BHJ PSCs has reached $11 \%{ }^{5-7}$ Different strategies including device engineering (thermal annealing, solvent annealing, adding additives etc.) ${ }^{8,9}$ and developing new donor and acceptor materials have been used to improve the photovoltaic performance. ${ }^{10-18}$ Tremendous effort was put forward to developing new donor materials to achieve high efficiency PSCs. ${ }^{19-23}$ The absorption, energy level and charge mobility of polymers and even the morphology of blend films can be modulated by polymer structure engineering. ${ }^{24-29}$ The design of polymers with a donor (D)-acceptor (A) alternating structure is an effective way to broaden their absorption. ${ }^{30-33}$ The introduction of fluorine atoms onto either donor unit or acceptor unit of the polymers can enhance the crystallization of polymers and decrease their energy levels, ${ }^{34-39}$ due to its strong electron-withdrawing nature and the ability of forming noncovalent bond between fluorine and hydrogen or sulfur atom $(\mathrm{F} \cdots \mathrm{H}$ or F ...S). However, the change of surface energy caused by fluorine substitution may spoil the blend film morphology and lead to serious phase separation. ${ }^{33,40-42}$ Therefore, it is highly demanded to investigate the effect of fluorination on the energy level, charge mobility, film morphology and device performance.

Although the introduction of fluorine atoms on the D or A unit has been widely used in the synthesis of conjugated donor materials, the systematic investigation of the influence of fluoro substitution position and number on the optical, electrochemical and photovoltaic properties of conjugated polymers was seldom reported. ${ }^{43}$ Here we designed and synthesized a series of fluorinated D-A alternating conjugated polymers (PHF, PFH and PFF) to explore their structure property relationship. The chemical structures of these polymers are shown in Chart 1. PHF contains two fluoro substituents on the two lateral phenyl groups; PFH comprises two fluoro substituents on the polymer main chain; and PFF contains two fluoro substituents on the lateral 
phenyl groups and two fluoro atoms on the polymer backbone. The influence of fluoro substitution (number and position) on the energy level, charge mobility, morphology and photovoltaic performance was systematically investigated. PFH based PSCs displayed a PCE of $6.19 \%$ with a $V_{\mathrm{oc}}$ of $0.93 \mathrm{~V}$, a $J_{\mathrm{sc}}$ of $9.57 \mathrm{~mA} / \mathrm{cm}^{2}$ and an $F F$ of 0.70 ; PHF based PSCs displayed a PCE of $7.2 \%$ with a $V_{\text {oc }}$ of $0.84 \mathrm{~V}$, a $J_{\text {sc }}$ of $12.46 \mathrm{~mA} / \mathrm{cm}^{2}$ and an $F F$ of 0.69 ; and PFF based PSCs only afforded a PCE of $2.9 \%$ with a $V_{\text {oc }}$ of $0.92 \mathrm{~V}$, a $J_{\mathrm{sc}}$ of $4.61 \mathrm{~mA} / \mathrm{cm}^{2}$ and an $F F$ of 0.68 . Morphology investigations revealed that $\mathbf{P F F}: \mathrm{PC}_{71} \mathrm{BM}$ blend films formed large aggregates due to the introduction of four fluorine atoms at each repeating unit, which decreased the surface energy of polymers.

Chart 1. Chemical structures of PFF, PHF and PFH

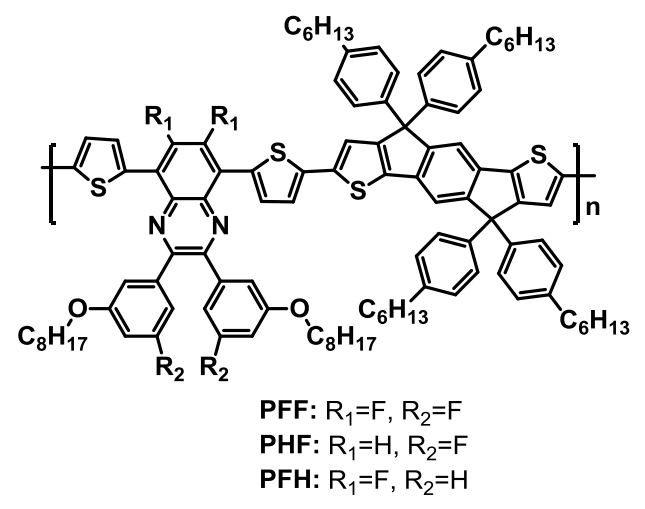

\section{Results and discussion}

\section{Material Synthesis and Characterization}

Scheme 1. Synthetic routes of M1, M2 and PFF, PHF and PFH. 

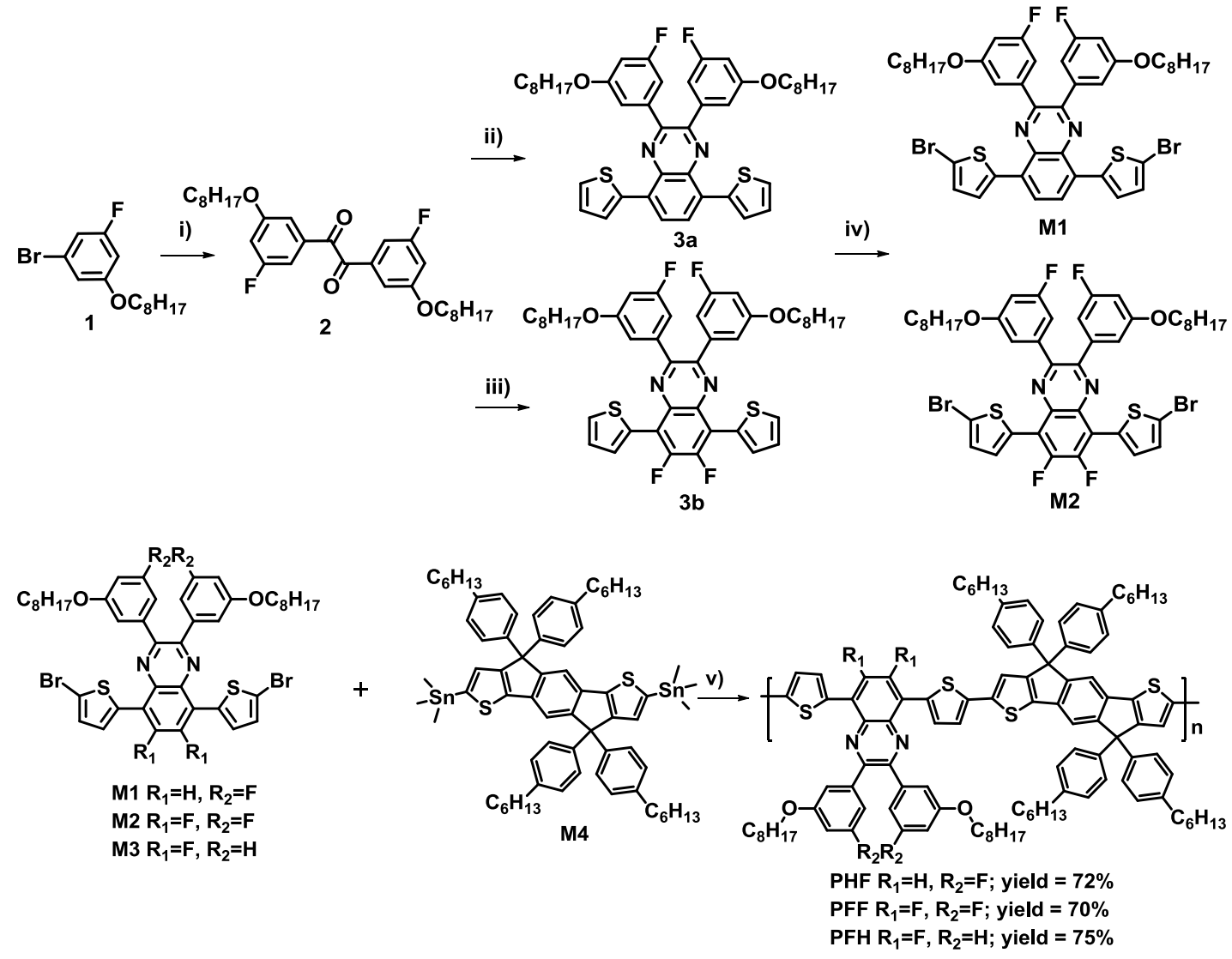

i) $\mathrm{n}-\mathrm{BuLi}, \quad \mathrm{CuBr}, \mathrm{LiBr}, \quad$ oxalyl dichloride, $\mathrm{THF}, \quad-78 \quad{ }^{\circ} \mathrm{C}$; $\quad$ ii) 5,6-difluoro-4,7-di(thiophen-2-yl)benzo[c][1,2,5]thiadiazole, $\mathrm{Zn}, \mathrm{CH}_{3} \mathrm{COOH}, 70{ }^{\circ} \mathrm{C}$. iii) 4,7-di(thiophen-2-yl)benzo[c][1,2,5]thiadiazole, $\mathrm{Zn}, \mathrm{CH}_{3} \mathrm{COOH}, 70{ }^{\circ} \mathrm{C}$. iv) NBS, $\mathrm{CHCl}_{3}, \mathrm{DMF}$, rt; v) $\mathrm{Pd}\left(\mathrm{PPh}_{3}\right)_{4}$, toluene/DMF, reflux.

Syntheses of monomers (M1 and M2) and polymers (PHF, PFH and PFF) are outlined in Scheme 1. Polymers PHF (PFH or PFF) were synthesized by Stille polycondensation of M1 (M2 or M3) with M4, respectively, and the detailed procedures are described in Supporting Information. These polymers are of good solubility in common organic solvents such as dichloromethane, tetrahydrofuran, chloroform, toluene, chlorobenzene (CB) and dichlorobenzene (DCB) at room temperature. The molecular weight and molecular weight distribution were determined by gel permeation chromatography (GPC) using CB as an eluent at $80{ }^{\circ} \mathrm{C}$ calibrated with polystyrene standards and the results are summarized in Table 1 . The number-average molecular weights $\left(M_{\mathrm{n}}\right)$ and polydispersity index (PDI) are 52.7 $\mathrm{Kg} / \mathrm{mol}$ and 2.61 for PHF, $54.9 \mathrm{Kg} / \mathrm{mol}$ and 1.59 for PFH, and $63.2 \mathrm{Kg} / \mathrm{mol}$ and 2.21 for PFF. Thermal gravimetric analysis (TGA) showed that these polymers are of good 
thermal stability with the $5 \%$ decomposition temperature up to $448{ }^{\circ} \mathrm{C}$ for $\mathbf{P H F}$ and PFH, $440{ }^{\circ} \mathrm{C}$ for PFF and the data are summarized in Table 1.

Table 1. Molecular Weights and Thermal Properties of Copolymers

\begin{tabular}{ccccc}
\hline Polymer & $\mathrm{T}_{\mathrm{d}}\left({ }^{\circ} \mathrm{C}\right)$ & $M_{\mathrm{n}}(\mathrm{Kg} / \mathrm{mol})$ & $M_{\mathrm{w}}(\mathrm{Kg} / \mathrm{mol})$ & PDI \\
\hline PHF & 448 & 52.7 & 137.7 & 2.61 \\
PFH & 448 & 54.9 & 87.4 & 1.59 \\
PFF & 440 & 63.2 & 139.8 & 2.21 \\
\hline
\end{tabular}

\section{Optical and electrochemical properties}

To investigate the optical properties of these copolymers, the ultraviolet-visible (UV) absorption spectra were measured. As shown in Figure 1, in dilute solutions these polymers displayed a broad absorption ranging from 400-700 $\mathrm{nm}$ with two distinct peaks located at 457 and $603 \mathrm{~nm}$ for PHF, 442 and $589 \mathrm{~nm}$ for PFH, and 452 and 607 $\mathrm{nm}$ for PFF. For all polymers, the side chains, which perpendicular to the polymer main chain (Figure S2), could effectively prevent the polymer main chains from forming close packing in the solid state. Therefore, these polymers exhibited a good solubility in most commonly used organic solvents as mentioned before. The unique structure of these polymers could well elucidate that there is almost no red-shift for absorption spectra of PHF and PFH in going from solution to film. As for PFF, there is only an $11 \mathrm{~nm}$ red-shift in going from solution to film, indicating it may form closer packing than those two polymers. These results demonstrated that these polymers probably form amorphous films. The optical band gaps $\left(E_{\mathrm{g}, \mathrm{opt}}\right)$ of PHF, PFH and PFF were calculated to be $1.74,1.82$ and $1.74 \mathrm{eV}$, respectively, by equation of $E_{\mathrm{g}, \mathrm{opt}}=$ $1240 / \lambda_{\text {edge }}$ The optical band gap is related to the electron withdrawing ability of acceptor unit and the electron donating ability of donor unit. Due to the strong electron withdrawing ability, the introduction of fluorine atom on different positions of the acceptor unit has different influence on the electron withdrawing ability of acceptor unit. The introduction of fluorine atom on the meta position of lateral phenyl group may have more significant influence to the electron withdrawing ability of acceptor unit than that on the polymer main chain. ${ }^{44-48}$ 

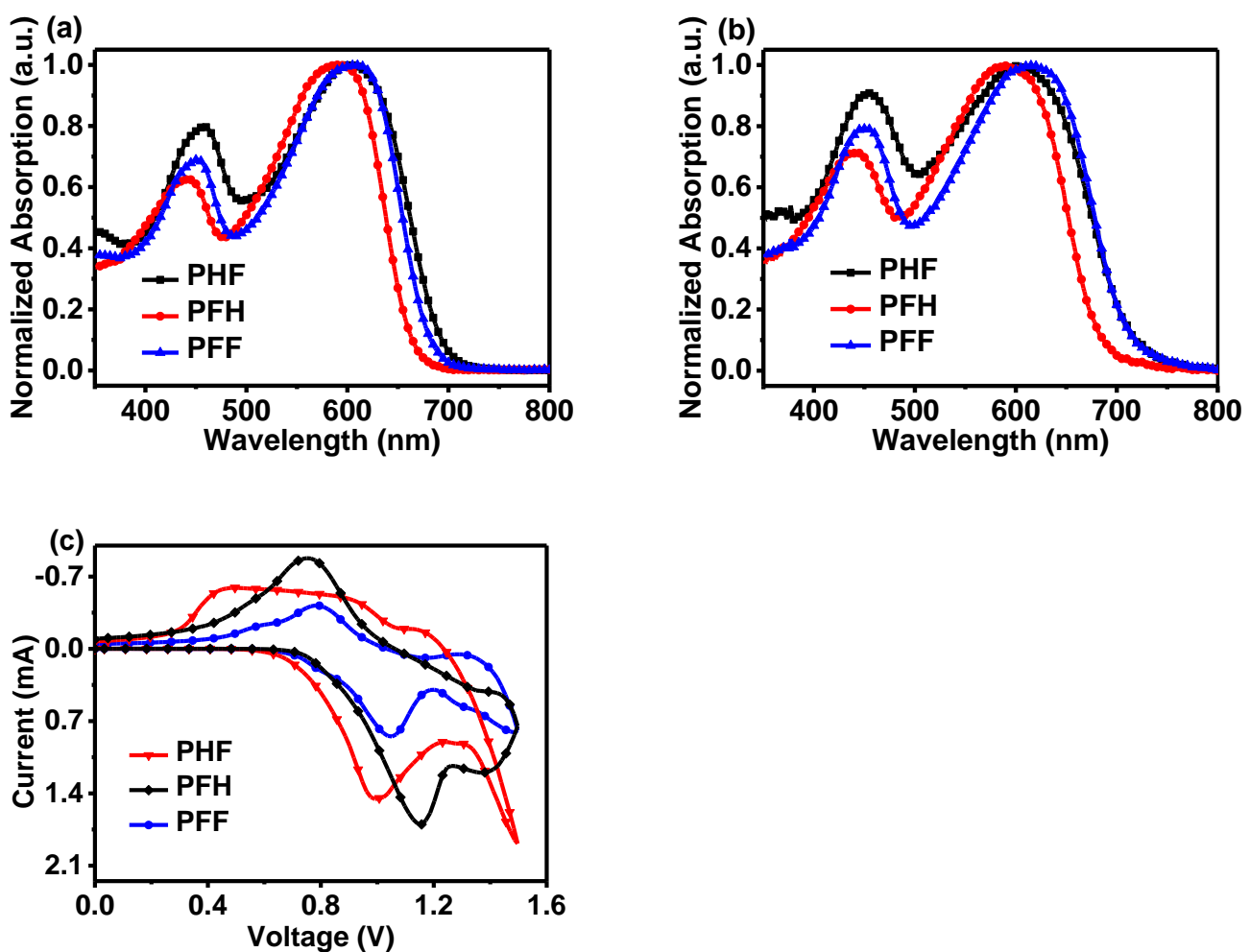

Figure 1. a) UV-visible absorption spectra of PHF (PFH or PFF) in dilute DCB solutions at room temperature; b) UV-visible absorption spectra of PHF (PFH or PFF) as film; c) Cyclic voltammograms of PHF (PFH or PFF) as film on the platinum electrode in $0.1 \mathrm{M} \mathrm{Bu}_{4} \mathrm{NPF}_{6}$ acetonitrile solution at a scan rate of $50 \mathrm{mV} / \mathrm{s}$.

Cyclic voltammograms of PHF (PFH or PFF) as film was measured on the platinum electrode in a standard three-electrode electrochemical cell. As shown in Figure 1c, the onset oxidation potentials of PHF, PFH and PFF were determined to be 0.65, 0.72 and $0.72 \mathrm{~V}$, respectively. According to the equation: $E_{\mathrm{HOMO}}=-\left(E_{\mathrm{Ox}}+4.71\right) \mathrm{eV}$, the HOMO energy levels of PHF, PFH and PFF were calculated to be $-5.36,-5.43$ and $-5.43 \mathrm{eV}$, respectively. It can be seen that fluoro substitution at the lateral phenyl groups of DTQx has little effect on the onset oxidation potential of polymers; whereas, the introduction of fluorine atoms onto the polymer backbone could markedly lower the HOMO energy levels of polymers PFH and PFF. LUMO energy levels of polymers were calculated by equation: $E_{\mathrm{LUMO}}=E_{\mathrm{HOMO}}+E_{\mathrm{g}, \mathrm{opt}}$ to be $-3.62,-3.61$ and $-3.69 \mathrm{eV}$ for PHF, PFH and PFF, respectively. The results are listed in Table 2. 
Table 2. Optical and electrochemical properties of PFF (PFH or PFF)

\begin{tabular}{lllllll}
\hline Polymer & $\lambda_{\max }(\mathrm{nm})^{\mathrm{a}}$ & $\lambda_{\max }(\mathrm{nm})^{\mathrm{b}}$ & $\lambda_{\text {edge }}(\mathrm{nm})^{\mathrm{b}}$ & $\mathrm{E}_{\mathrm{g}, \text { opt }}(\mathrm{eV})^{\mathrm{c}}$ & HOMO $(\mathrm{eV})$ & ${\text { LUMO }(\mathrm{eV})^{\mathrm{d}}}^{\text {H }}$ \\
\hline PHF & 457,603 & 455,603 & 714 & 1.74 & -5.36 & -3.62 \\
PFH & 442,589 & 442,589 & 680 & 1.82 & -5.43 & -3.61 \\
PFF & 452,607 & 450,618 & 714 & 1.74 & -5.43 & -3.69 \\
\hline
\end{tabular}

${ }^{\mathrm{a}}$ In solutions at room temperature; ${ }^{\mathrm{b}}$ As films; ${ }^{\mathrm{c}}$ Calculated from the absorption band edge of copolymer films, $E_{\mathrm{g}, \mathrm{opt}}=1240 / \lambda_{\text {edge; }}{ }^{\mathrm{d}}$ Calculated by the equation $E_{\mathrm{LUMO}}=$ $E_{\mathrm{HOMO}}+E_{\mathrm{g}, \mathrm{opt}}$

\section{Photovoltaic properties}

To evaluate the photovoltaic properties of polymer PHF (PFH or PFF), devices with a structure of ITO/PEDOT:PSS/Polymer:PC ${ }_{71} \mathrm{BM} / \mathrm{LiF} / \mathrm{Al}$ were fabricated. The optimized devices were fabricated in a polymer: $\mathrm{PC}_{71} \mathrm{BM}$ weight ratio of $1: 4$ in a solvent mixture of DCB and 1-chloronaphthalene (98:2, by volume). The best PCE of $7.2 \%$ was achieved with a $V_{\mathrm{oc}}$ of $0.84 \mathrm{~V}$, a $J_{\mathrm{sc}}$ of $12.46 \mathrm{~mA} / \mathrm{cm}^{2}$ and an $F F$ of 0.69 for PHF based solar cells. For PFH and PFF based solar cells, higher $V_{\text {oc }}$ can be expected due to their deeper HOMO energy levels since the $V_{\text {oc }}$ is related with the difference between HOMO energy level of donor materials and LUMO energy level of acceptor materials. A PCE of $6.19 \%$ with a high $V_{\text {oc }}$ of $0.93 \mathrm{~V}$, a $J_{\text {sc }}$ of $9.57 \mathrm{~mA} / \mathrm{cm}^{2}$ an $F F$ of 0.70 was obtained for PFH based solar cells. Compared with PHF, narrower absorption of PFH might result in decreased $J_{\text {sc }}$. A very low PCE of $2.90 \%$ with a $V_{\text {oc }}$ of $0.92 \mathrm{~V}$, a low $J_{\mathrm{sc}}$ of $4.61 \mathrm{~mA} / \mathrm{cm}^{2}$ and an $F F$ of 0.68 for PFF based solar cells was acquired under the optimized conditions. Both the hole mobility and morphology of PFF based blend layer could illuminate its low photovoltaic performance. The data are summarized in Table 3 and the related $J$ - $V$ curves of devices fabricated under optimized conditions are shown in Figure 2a. The EQE curves of optimized devices are shown in Figure 2b. The $J_{\mathrm{sc}}$ values obtained from $J-V$ measurements are close to the current densities calculated by the integration of EQE curves, which verified the accuracy of the $J-V$ measurement. 
Table 3. Optical performance of PHF (PFH or PFF) based solar cells under optimized conditions.

\begin{tabular}{|c|c|c|c|c|c|c|}
\hline \multirow{4}{*}{ Polymer } & \multirow{4}{*}{$\begin{array}{c}\text { PCE } \\
\text { (Average) } \\
(\%)\end{array}$} & \multirow{4}{*}{$\begin{array}{c}J_{\mathrm{sc}} \\
{\left[\mathrm{mA} / \mathrm{cm}^{2}\right]}\end{array}$} & \multirow{4}{*}{$\begin{array}{l}V_{\mathrm{oc}} \\
{[\mathrm{V}]}\end{array}$} & \multirow{4}{*}{$F F$} & Hole & \multirow{4}{*}{$\begin{array}{c}\text { Thickness } \\
\text { (nm) }\end{array}$} \\
\hline & & & & & Mobility & \\
\hline & & & & & SCLC & \\
\hline & & & & & $\left(\mathrm{cm}^{2} \mathrm{~V}^{-1} \mathrm{~s}^{-1}\right)$ & \\
\hline PHF & $7.20(6.95)$ & 12.46 & 0.84 & 0.69 & $3.5 \times 10^{-5}$ & 215 \\
\hline PFH & $6.19(5.96)$ & 9.57 & 0.93 & 0.70 & $1.2 \times 10^{-5}$ & 98 \\
\hline PFF & $2.90(2.79)$ & 4.61 & 0.92 & 0.68 & $1.1 \times 10^{-6}$ & 105 \\
\hline
\end{tabular}
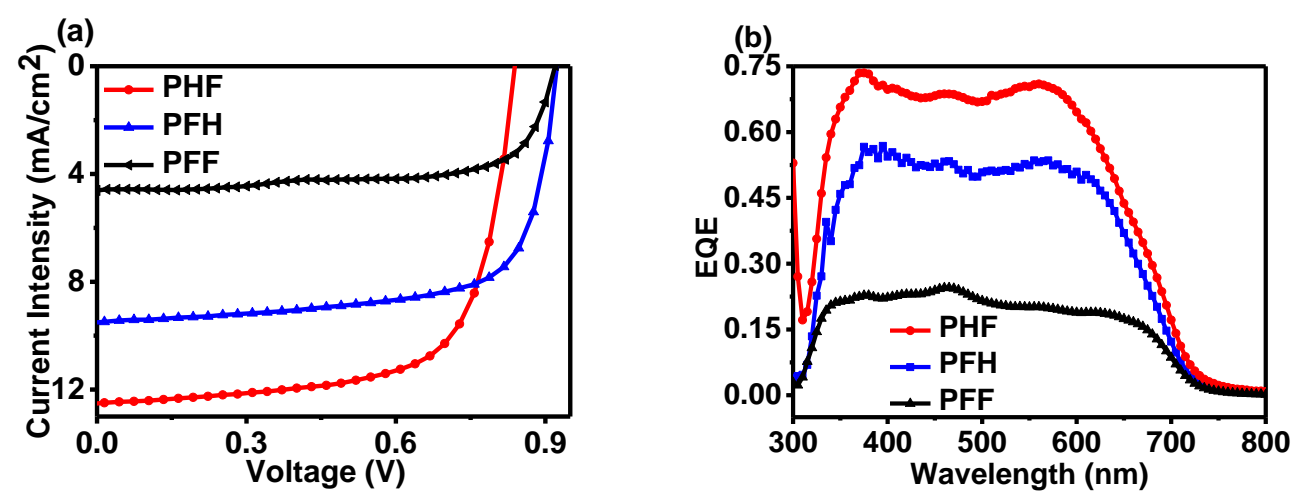

Figure 2. a) $J-V$ and b) EQE curves of PHF (PFH or PFF) based solar cells under optimized conditions.

Hole mobilities of PHF (PFH or PFF) based devices were determined by SCLC method with a device structure of ITO/PEDOT:PSS/Polymer:PC ${ }_{71} \mathrm{BM} / \mathrm{Au}$ to provide insight into charge mobility performance of polymers. The active layer thicknesses of devices and the results are listed in Table 3 . Hole mobilities of $3.5 \times 10^{-5}, 1.2 \times 10^{-5}$, and $1.1 \times 10^{-6} \mathrm{~cm}^{2} \mathrm{~V}^{-1} \mathrm{~s}^{-1}$ were obtained for PHF:PC ${ }_{71} \mathrm{BM}, \mathbf{P F H}: \mathrm{PC}_{71} \mathrm{BM}$ and PFF: $\mathrm{PC}_{71} \mathrm{BM}$ blend films, respectively. It is reasonable that PHF and PFH gave high hole mobility as well as high photovoltaic performance. The low hole mobility of PFF:PC ${ }_{71} \mathrm{BM}$ based devices is probably originatedI from its poor morphology (vide infra) and increased effect of bimolecular recombination. ${ }^{33}$

\section{Morphology}

To profoundly reveal what caused the photovoltaic performance difference of these 
three polymers, the nanoscale phase separation of the blend films was investigated by Resonant soft X-ray scattering (R-SoXS). A photon energy of $284.2 \mathrm{eV}$ is selected to provide highly enhanced contrast between components. As shown in Figure 3, the blend films based on PHF:PC ${ }_{71} \mathrm{BM}$ and PFH:PC ${ }_{71} \mathrm{BM}$ exhibited adjacent peaks located at $\mathrm{q} \approx 0.069 \mathrm{~nm}^{-1}$ and $\mathrm{q} \approx 0.064 \mathrm{~nm}^{-1}$, corresponding to characteristic phase separation length scale of about $91 \mathrm{~nm}$ and $98 \mathrm{~nm}$ by the calculated mold of $2 \pi / \mathrm{q}$, respectively. As for PFF:PC ${ }_{71} \mathrm{BM}$ based blend films, two noteworthy peaks located at $\mathrm{q} \approx 0.024 \mathrm{~nm}^{-1}$ and $\mathrm{q} \approx 0.044 \mathrm{~nm}^{-1}$ were observed, indicating that two phase regions existed in the blend film with very large phase separation scale of about 260 and 140 $\mathrm{nm}$, respectively. The formation of large phase separation, which is not beneficial for charge separation, is consistent with the low PCE and $J_{\text {sc }}$ for PFF based solar cells.

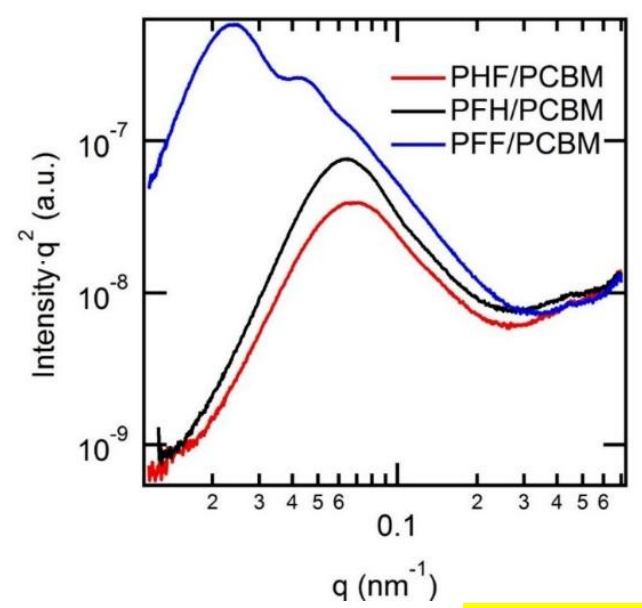

Figure 3. R-SoXS profiles in log scale for PHF (PFH or PFF)based active layers spin-coated under optimized conditions

The morphology of polymer: $\mathrm{PC}_{71} \mathrm{BM}$ blend films was also investigated by transmission electron microscopy (TEM) and the TEM images are shown in Figure 4. The PHF:PC ${ }_{71} \mathrm{BM}$ and PFH:PC ${ }_{71} \mathrm{BM}$ exhibited a homogenous morphology without large scale phase separation; whereas for the PFF: $\mathrm{PC}_{71} \mathrm{BM}$ blend films, spherical domains in a diameter of about $200 \mathrm{~nm}$ were observed. It is worthy to note that TEM and R-SoXS results are fully consistent. Since the introduction of fluorine atoms onto polymers can decrease the surface energy of the resulted polymers and change the intermolecular interactions between polymers and $\mathrm{PC}_{71} \mathrm{BM}$, therefore it is reasonable that fluoro substitution on the polymers can alter the morphology of blend films. 
Usually, fluorinated polymers showed a very low energy surface.
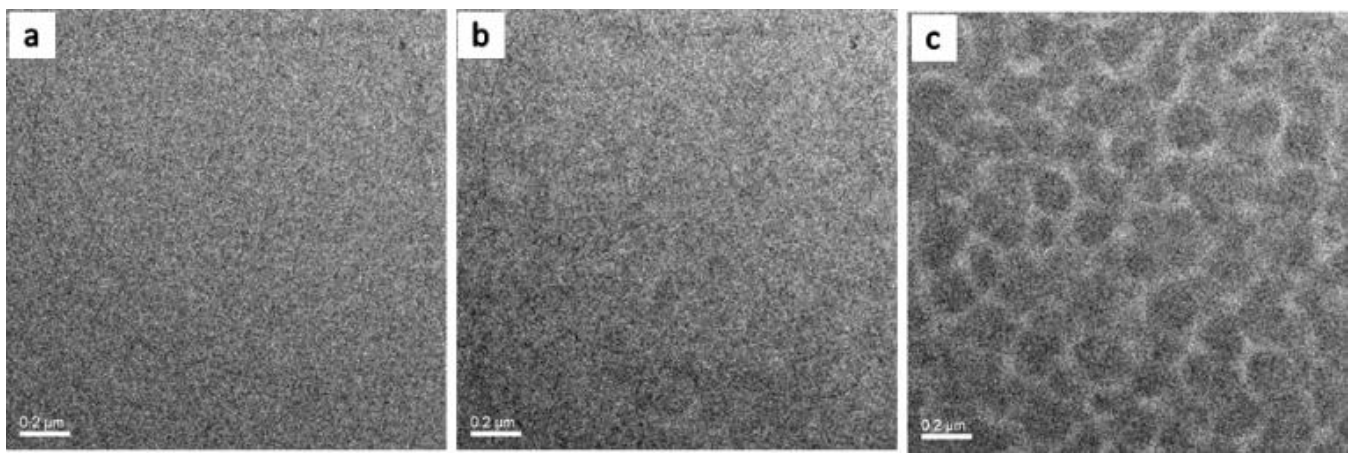

Figure 4. TEM images of a) PHF, b) PFH and c) PFF based blend layers. The scale bar is $200 \mathrm{~nm}$.

\section{Conclusion}

Three novel D-A alternating fluorinated polymers PHF, PFH and PFF were synthesized by Stille reaction of 2,3-diphenyl-5,8-di(thiophen-2-yl)quinoxaline (DTQx) based dibromo monomers (M1, M2 and M3) and indacenodithiophene (IDT) based bis(trimthylstannyl) monomer (M4). The number and position of fluorine atoms on the polymers have a significant influence on the optical, electrochemical and photovoltaic properties of polymers. As films, all these polymers exhibited a broad absorption ranging from 350 to $750 \mathrm{~nm}$. PFH and PFF with the fluoro substitution on the polymer main chain showed deeper HOMO and LUMO energy level than PHF with the fluoro substitution only at the side chain. PHF based devices achieved a high PCE of $7.2 \%$ with a $V_{\text {oc }}$ of $0.84 \mathrm{~V}$, a $J_{\text {sc }}$ of $12.46 \mathrm{~mA} / \mathrm{cm}^{2}$ and an $F F$ of 0.69 , and PFH based devices afforded a PCE of $6.19 \%$ with a high $V_{\mathrm{oc}}$ of $0.93 \mathrm{~V}, J_{\mathrm{sc}}$ of $9.57 \mathrm{~mA} / \mathrm{cm}^{2}$ and $F F$ of 0.70 . However, PFF based devices only gave a PCE of $2.9 \%$ with $V_{\mathrm{oc}}$ of $0.92 \mathrm{~V}$, a low $J_{\mathrm{sc}}$ of $4.61 \mathrm{~mA} / \mathrm{cm}^{2}$ and an $F F$ of 0.68 . The introduction of four fluorine atoms at each repeat unit could markedly influence the morphology of polymer: $\mathrm{PC}_{71} \mathrm{BM}$ blend films and resulted in large spherical domains.

\section{Acknowledgements}

Financial support from the NSF of China (91233205, 21574013 and 51003006), 
Beijing Natural Science Foundation (2132042), Program for Changjiang Scholars and Innovative Research Team in University and the Fundamental Research Funds for the Central Universities are gratefully acknowledged.

\section{References}

1 S. Gunes, H. Neugebauer and N. S. Sariciftci, Conjugated polymer-based organic solar cells. Chem. Rev., 2007, 107, 1324-1338.

2 Y. Cheng, S. Yang and C. Hsu, Synthesis of Conjugated Polymers for Organic Solar Cell Applications. Chem. Rev., 2009, 109, 5868-5923.

3 Y. Huang, E. J. Kramer, A. J. Heeger and G. C. Bazan, Bulk Heterojunction Solar Cells: Morphology and Performance Relationships. Chem. Rev., 2014, 114, 7006-7043.

4 J. Roncali, Molecular Bulk Heterojunctions: An Emerging Approach to Organic Solar Cells. Acc. Chem. Res., 2009, 42, 1719-1730.

5 J. Zhao, Y. Li, G. Yang, K. Jiang, H. Lin, H. Ade, W. Ma and H. Yan, Efficient organic solar cells processed from hydrocarbon solvents. Nature Energy, 2016, 1, 15027.

6 L. Nian, K. Gao, F. Liu, Y. Kan, X. Jiang, L. Liu, Z. Xie, X. Peng, T. P. Russell and Y. Ma, 11\% Efficient Ternary Organic Solar Cells with High Composition Tolerance via Integrated Near-IR Sensitization and Interface Engineering. Adv. Mater., 2016, 28, 8184-8190.

7 Z. He, B. Xiao, F. Liu, H. Wu, Y. Yang, S. Xiao, C. Wang, T. P. Russell and Y. Cao, Single-junction polymer solar cells with high efficiency and photovoltage. Nat. Photonics, 2015, 9, 174-179.

8 Q. Mei, C. H. Li, X. Gong, H. Lu, E. Jin, C. Du, Z. Lu, L. Jiang, X. Meng, C. Wang and Z. Bo, Enhancing the Performance of Polymer Photovoltaic Cells by 
Using an Alcohol Soluble Fullerene Derivative as the Interfacial Layer. Acs App. Mater. Interfaces, 2013, 5, 8076-8080.

9 H. Ma, H. Yip, F. Huang and A. K. Y. Jen, Interface Engineering for Organic Electronics. Adv. Funct. Mater., 2010, 20, 1371-1388.

10H. Zhang, L. Ye and J. Hou, Molecular design strategies for voltage modulation in highly efficient polymer solar cells. Polym. Int., 2015, 64, 957-962.

11 M. Zhang, X. Guo, W. Ma, S. Zhang, L. Huo, H. Ade and J. Hou, An Easy and Effective Method to Modulate Molecular Energy Level of the Polymer Based on Benzodithiophene for the Application in Polymer Solar Cells. Adv. Mater., 2014, 26, 2089-2095.

12 N. Wang, Z. Chen, W. Wei and Z. Jiang, Fluorinated Benzothiadiazole-Based Conjugated Polymers for High-Performance Polymer Solar Cells without Any Processing Additives or Post-treatments. J. Am. Chem. Soc., 2013, 135, 17060-17068.

13 H. Wei, Y. Chao, C. Kang, C. Li, H. Lu, X. Gong, H. Dong, W. Hu, C. Hsu and Z. Bo, High-Efficiency Large-Bandgap Material for Polymer Solar Cells. Macromol. Rapid Commun., 2015, 36, 84-89.

14C. Cui, W. Wong and Y. Li, Improvement of open-circuit voltage and photovoltaic properties of $2 \mathrm{D}$-conjugated polymers by alkylthio substitution. Energy \& Environ. Sci., 2014, 7, 2276-2284.

15C. Cui, Z. He, Y. Wu. Cheng, H. Wu, Y. Li, Y. Cao and W. Wong, High-performance polymer solar cells based on a 2D-conjugated polymer with an alkylthio side-chain. Energy \& Environ. Sci., 2016, 9, 885-891.

16Z. Lu, C. Li, C. Du, X. Gong and Z. Bo, 6,7-dialkoxy-2,3-diphenylquinoxaline based conjugated polymers for solar cells with high open-circuit voltage. Chin. J. Polym. Sci., 2013, 31, 901-911.

17 H. Wei, H. Lu, T. Fang and Z. Bo, Evaluating the photovoltaic properties of two conjugated polymers synthesized by Suzuki polycondensation and direct C-H activation. Sci. China-Chem., 2015, 58, 286-293. 
18 Y. Chen, S. Zhang, Y. Wu and J. Hou, Molecular Design and Morphology Control Towards Efficient Polymer Solar Cells Processed using Non-aromatic and Non-chlorinated Solvents. Adv. Mater., 2014, 26, 2744-2749.

19L. Bian, E. Zhu, J. Tang, W. Tang and F. Zhang, Recent progress in the design of narrow bandgap conjugated polymers for high-efficiency organic solar cells. Prog. Polym. Sci., 2012, 37, 1292-1331.

20 J. Hou, N. Ye, S. Liao, Y. Li, Y. Cheng and S. Chen, Review on the Recent Progress in Low Band Gap Conjugated Polymers for Bulk Hetero-junction Polymer Solar Cells. J. Chin. Chem. Soc., 2014, 61, 115-126.

21 M. Zhang, X. Guo, S. Zhang and J. Hou, Synergistic Effect of Fluorination on Molecular Energy Level Modulation in Highly Efficient Photovoltaic Polymers.Adv. Mater., 2014, 26, 1118-1123.

22 H. Yao; L. Ye; H. Zhang; S. Li; S. Zhang; J. Hou, Molecular Design of Benzodithiophene-Based Organic Photovoltaic Materials. Chem. Rev. 2016, $116,7397-7457$.

23 H. Yao; J. Hou, Design and Application of Highly Efficient Polymers for Polymer Solar Cells. Acta Polymerica Sinica 2016, 1468-1481.

24X. Zhan, Z. a. Tan, B. Domercq, Z. An, X. Zhang, S. Barlow, Y. Li, D. Zhu, B. Kippelen and S. R. Marder, A high-mobility electron-transport polymer with broad absorption and its use in field-effect transistors and all-polymer solar cells. J. Am. Chem. Soc., 2007, 129, 7246-7247.

25 J. W. Jo, J. W. Jung, E. H. Jung, H. Ahn, T. J. Shin and W. H. Jo, Fluorination on both $\mathrm{D}$ and $\mathrm{A}$ units in D-A type conjugated copolymers based on difluorobithiophene and benzothiadiazole for highly efficient polymer solar cells. Energy \& Environ. Sci., 2015, 8, 2427-2434.

26D. Lee, E. Hubijar, G. J. D. Kalaw and J. P. Ferraris, Enhanced and Tunable Open-Circuit Voltage using Dialkylthio Benzo 1,2-b:4,5-b ' dithiophene in Polymer Solar Cells. Chem. Mater., 2012, 24, 2534-2540.

27 G. Li, C. Kang, X. Gong, J. Zhang, C. Li, Y. Chen, H. Dong, W. Hu, F. Li and Z. Bo, 5-Alkyloxy-6-fluorobenzo[c][1,2,5]thiadiazole- and Silafluorene-Based 
D-A Alternating Conjugated Polymers: Synthesis and Application in Polymer Photovoltaic Cells. Macromolecules, 2014, 47, 4645-4652.

28 W. Li, W. S. C. Roelofs, M. M. Wienk and R. A. J. Janssen, Enhancing the Photocurrent in Diketopyrrolopyrrole-Based Polymer Solar Cells via Energy Level Control. J. Am. Chem. Soc., 2012, 134, 13787-13795.

29 Y. Liu, J. Zhao, Z. Li, C. Mu, W. Ma, H. Hu, K. Jiang, H. Lin, H. Ade and H. Yan, Aggregation and morphology control enables multiple cases of high-efficiency polymer solar cells. Nat. Commun., 2014, 5.

30H. A. M. van Mullekom, J. Vekemans, E. E. Havinga and E. W. Meijer, Developments in the chemistry and band gap engineering of donor-acceptor substituted conjugated polymers. Mater. Sci. Engin. R-Rep., 2001, 32, 1-40.

31E. Bundgaard and F. C. Krebs, Low band gap polymers for organic photovoltaics. Sol. Energy Mater. Sol. Cells, 2007, 91, 954-985.

32C. Duan, F. Huang and Y. Cao, Recent development of push-pull conjugated polymers for bulk-heterojunction photovoltaics: rational design and fine tailoring of molecular structures. J. Mater. Chem., 2012, 22, 10416-10434.

33 Y. Li, Molecular Design of Photovoltaic Materials for Polymer Solar Cells: Toward Suitable Electronic Energy Levels and Broad Absorption. Acc. Chem. Res., 2012, 45, 723-733.

34 S. C. Price, A. C. Stuart, L. Yang, H. Zhou and W. You, Fluorine Substituted Conjugated Polymer of Medium Band Gap Yields 7\% Efficiency in Polymer-Fullerene Solar Cells. J. Am. Chem. Soc., 2011, 133, 4625-4631.

35 A. C. Stuart, J. R. Tumbleston, H. Zhou, W. Li, S. Liu, H. Ade and W. You, Fluorine Substituents Reduce Charge Recombination and Drive Structure and Morphology Development in Polymer Solar Cells. J. Am. Chem. Soc., 2013, 135, 1806-1815.

36H. J. Son, W. Wang, T. Xu, Y. Liang, Y. Wu, G. Li and L. Yu, Synthesis of Fluorinated Polythienothiophene-co-benzodithiophenes and Effect of Fluorination on the Photovoltaic Properties. J. Am. Chem. Soc., 2011, 133, 1885-1894. 
37 K. Wang, B. Guo, Z. Xu, X. Guo, M. Zhang and Y. Li, Solution-Processable Organic Molecule for High-Performance Organic Solar Cells with Low Acceptor Content. Acs App. Mater. Interfaces, 2015, 7, 24686-24693.

38C. Huang, J. Chang, S. Huang, K. Wu, J. Jheng, W. Chuang, C. Hsu and C. Wang, Polymorphisms and morphological studies of a difluorobenzothiadiazole conjugated copolymer with $7.8 \%$ polymer solar cell efficiency. J. Mater. Chem. A, 2015, 3, 3968-3974.

39Y. Zheng, Z. Wang, J. Dou, S. Zhang, X. Luo, Z. Yao, J. Wang and J. Pei, Effect of Halogenation in Isoindigo-Based Polymers on the Phase Separation and Molecular Orientation of Bulk Heterojunction Solar Cells. Macromolecules, 2015, 48, 5570-5577.

40D. Patwardhan, H. Zimmer and J. Mark, Synthesis of some fluorinated phenylmethylsiloxane polymers and characterization of their surface properties. J. Inorg. Organomet. Polym. Mater., 1997, 7, 93-109.

41 K. Kawashima; T. Fukuhara; Y. Suda; Y. Suzuki; T. Koganezawa; H. Yoshida; H. Ohkita; I. Osaka; K. Takimiya, Implication of Fluorine Atom on Electronic Properties, Ordering Structures, and Photovoltaic Performance in Naphthobisthiadiazole Based Semiconducting Polymers. J. Am. Chem. Soc. 2016, $138,10265-10275$.

42 B. C. Schroeder; Z. Huang; R. S. Ashraf; J. Smith; P. D'Angelo; S. E. Watkins; T. D. Anthopoulos; J. R. Durrant; I. McCulloch, Silaindacenodithiophene-Based Low Band Gap Polymers - The Effect of Fluorine Substitution on Device Performances and Film Morphologies. $A d v$. Funct. Mater. 2012, 22, 1663-1670.

43 D. Liu, W. Zhao, S. Zhang, L. Ye, Z. Zheng, Y. Cui, Y. Chen and J. Hou, Highly Efficient Photovoltaic Polymers Based on Benzodithiophene and Quinoxaline with Deeper HOMO Levels. Macromolecules, 2015, 48, $5172-5178$. 
44 J. W. Jo, J. H. Kim, J. W. Jung, Isoindigo-based fluorinated low band gap polymers for environmentally stable field effect transistor. Dyes and Pigments 2016, 133, 333-338.

45 H. Yao, Y. Cui, R. Yu, B. Gao, H. Zhang, J. Hou, Design, Synthesis, and Photovoltaic Characterization of a Small Molecular Acceptor with an Ultra-Narrow Band Gap. Angew. Chem. 2017, DOI: 10.1002/ange.201610944. 46 S. Dai, F. Zhao, Q. Zhang, T.-K. Lau, T. Li, K. Liu, Q. Ling, C. Wang, X. Lu, W. You, X. Zhan, Fused Nonacyclic Electron Acceptors for Efficient Polymer Solar Cells. J. Am. Chem. Soc. 2017, 139, 1336-1343.

47Zhang, Y.; Zou, J.; Cheuh, C.-C.; Yip, H.-L.; Jen, A. K. Y., Significant Improved Performance of Photovoltaic Cells Made from a Partially Fluorinated Cyclopentadithiophene/Benzothiadiazole Conjugated Polymer. Macromolecules 2012, 45, 5427-5435.

48 Wang, Z.; Xu, X.; Li, Z.; Feng, K.; Li, K.; Li, Y.; Peng, Q., Solution-Processed Organic Solar Cells with 9.8\% Efficiency Based on a New Small Molecule Containing a 2D Fluorinated Benzodithiophene Central Unit. Adv. Electron. Mater. 2016, 2.1600061. 


\section{Graphic abstract:}

Three novel donor-acceptor (D-A) alternative copolymers PHF, PFH and PFF were synthesized and applied for polymer solar cells (PSCs) to explore the influence of fluoro substitution position and number on optical, electrochemical and photovoltaic properties. PHF, PFH and PFF based PSCs gave power conversion efficiencies of $7.2 \%, 6.19 \%$ and $2.9 \%$, respectively. TEM and R-SoXS studies indicated that the introduction of four fluorine atoms at each repeating unit can spoil the morphology of active layer.
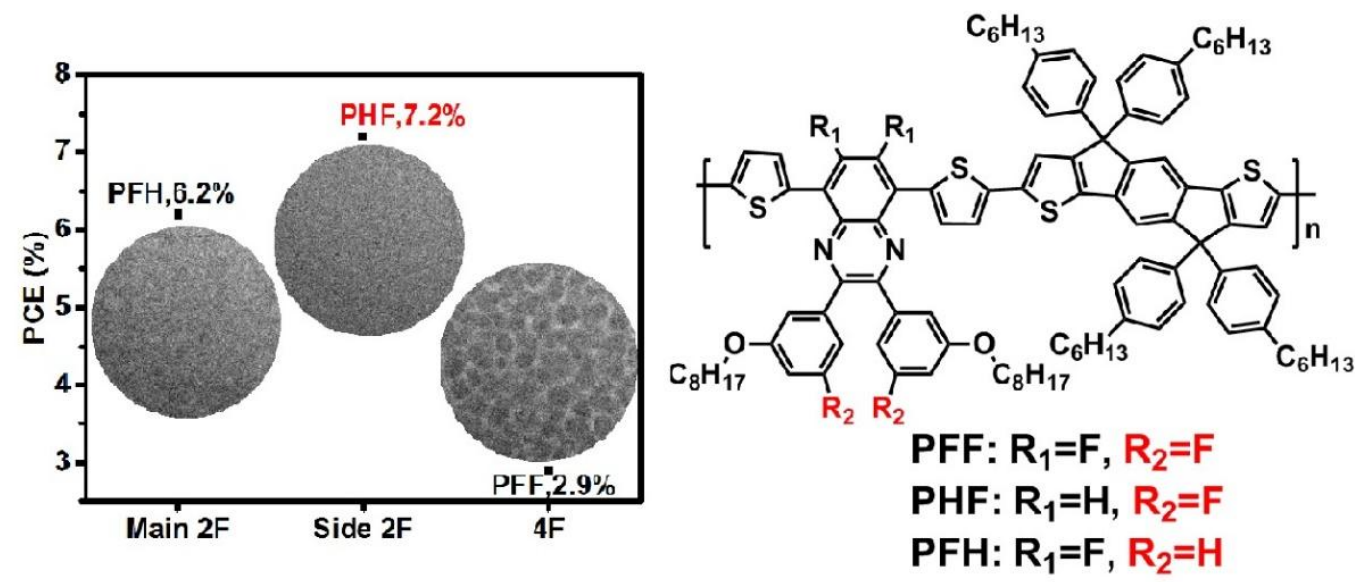

\section{Keywords:}

Polymer solar cells, fluorination position and number, morphology 